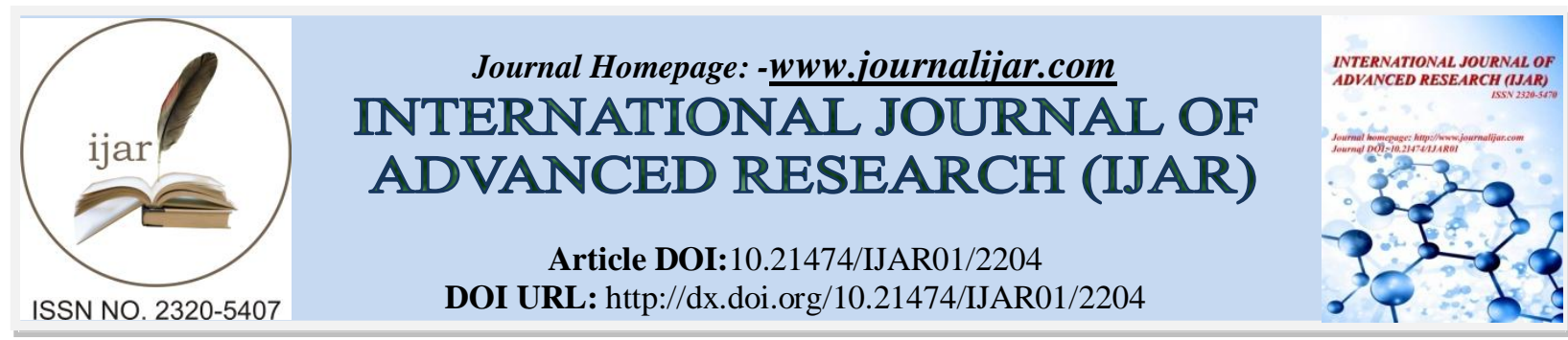

RESEARCH ARTICLE

\title{
ELECTROCHEMICALAND SURFACE CHARACTERIZATION STUDIES ON C38 STEEL IN 1 M HYDROCHLORIC ACID MEDIUM USING PROP-2-EN-1-ONE DERIVATIVES AS CORROSION INHIBITORS.
}

Jazi Abdullah Mohammed Abdulwahed ${ }^{1}$, R. M. Younis ${ }^{2}$, Hala. M. Hassan ${ }^{3}$, Marwa. R. Elsayad ${ }^{4}$ and A. M. Eldesoky ${ }^{* 5}$.

1. Physics Department, Umm Al-Qura University College in Qunfudah-Female-KSA.

2. Department of Chemistry, Faculty of Science, Mansoura University, Mansoura, Egypt and Faculty of Science, Chemistry Department, University of Tabuk, KSA.

3. Textile Technology Department, Industrial Education College, Beni-Suef University, Egypt and Chemistry Department, Faculty of Science, Jazan University, KSA.

4. Ophthalmology Dept., Faculty of Medicine, Mansoura University, Egypt and Al-Qunfudah Center for Scientific Research (QCSR), Chemistry Department, Al-Qunfudah University College, Umm Al-Qura University, KSA.

5. Engineering Chemistry Department, High Institute of Engineering \&Technology (New Damietta), Egypt and Al-Qunfudah Center for Scientific Research (QCSR), Chemistry Department, Al-Qunfudah University College, Umm Al-Qura University, KSA.

\section{Manuscript Info}

\section{Manuscript History}

Received: 28 September 2016

Final Accepted: 30 October 2016

Published: November 2016

Key words:-

C38 steel,EFM, Prop-2-en-1-one, SEMEDX.

\section{Abstract}

The inhibitive effect of prop-2-en-1-one derivatives against C38 steel and its adsorption behavior were investigated in $1 \mathrm{M} \mathrm{HCl}$ solution utilized tafel polarization, (EIS) electrochemical impedance spectroscopy and (EFM) electrochemical frequency modulation method. The data obtain from protective efficiency rise with the improving the dose of inhibitor. The orders of \% IE of prop-2-en-1-one derivatives are given: (1) >(2). The type of prop-2-en-1-one derivatives are mixed inhibitor whose adsorption habit onto C38 steel. EIS spectra exhibit one capacitive loop and confirm the protective ability. The surface morphology of inhibited C38 steel was analyzed by scanning electron microscope technology with energy dispersive $\mathrm{X}$-ray spectroscopy ((SEM-EDX).

Copy Right, IJAR, 2016,. All rights reserved.

\section{Introduction:-}

Corrosive arrangements are mainly utilized as a part of industry, for example, corrosive pickling of steel and iron, substance cleaning and preparing, generation of metal and well oil fermentation ${ }^{[1-3]}$. The issues increase from acid corrosion needed the improvement of different corrosion control methods among which the application of chemical inhibitors has been information as most economical tests for preclude corrosion of acid ${ }^{[4-9]}$. Numerous organic compounds, such as heterocyclic compounds, quaternary ammonium salts and acetylenic alcohol are generally utilized as inhibitors in different industries. The normal atoms adsorb on the metal surface among hetero atom, such as sulfur nitrogen and oxygen prevent the active sites and lead to a physical barrier to lower the transport of erosion species to the surface of metal ${ }^{[10-16]}$. Different inquires about uncovered that the influenced of adsorption not only the charge surface and nature of the metal, but also by the chemical assembled of inhibitors. The heterocyclic substances include $\mathrm{N}$ atoms, such as 4-aminoantipyrine are good corrosion protective with corrosive solution due to 
rise inhibition protection, best thermal stability and prevent the odor irritating for alloys and metals in different aggressive solution ${ }^{[17-22]}$. Therefore, the improve of novel adjuster inhibitors include 4-aminoantipyrineheterocyclic ring and the research of the relations among the chemicalstructure of inhibitors and their protection led to the higher significance in theoretical points and industrial.

In this study,the protection effect and electrochemical habit of prop-2-en-1-one derivatives for C38 steel contain $1 \mathrm{M}$ HClacid are given by the tafel polarization, (EIS) and (EFM) tests. SEM and EDX examination of the C38 steel in 1 $\mathrm{M} \mathrm{HCl}$ surface revealed that these compounds prevented $\mathrm{C} 38$ steel in $1 \mathrm{M} \mathrm{HCl}$ from corrosion by adsorption on its surface to form a protective film and acts as a barrier to corrosive media.

\section{Experimental Methods:-}

\section{Materials and Medium:-}

C38 steel was utilized for the calculation of corrosion. It's percent composition is $0.38 \mathrm{wt} . \% \mathrm{C}, 0.66 \mathrm{wt} . \% \mathrm{Mn}, 0.27$ wt. \% Si, 0.02 wt. \% S, 0.015 wt.\% P, 0.21 wt.\% Cr, 0.02 wt.\% Mo, 0.22 wt.\% Cu, 0.06 wt.\% $\mathrm{Al}$ and the remainder iron. The corrosion dose $(1 \mathrm{M} \mathrm{HCl})$ (37\%analytical grade) was ready by hydrochloric acid dilution with water double distilled. The organic inhibitors used in this study were some organic compounds ${ }^{[23]}$, listed in Table (1).

Table 1:-Molecular Formulas and Structure of Prop-2-en-1-one Derivatives.

\begin{tabular}{|l|c|c|c|c|}
\hline Compound No. & Mol. Wt. / M. Formula \\
\hline 2 & & Structure \\
2-en-1-one
\end{tabular}

\section{Methods:-}

Electrochemical Tests:-

Electrochemical tests were lead to three electrodes cell thermostatic utilized a Gamrypotentiostat/galvanostat/ZRA (model PCI300/4). A saturated calomel and platinum electrode were utilized as reference and auxiliary electrodes. The C38 steelelectrodes were $10 \times 10 \mathrm{ml}$ and were welded with a copper wire on one side. All methods were done at temperature $\left(25 \pm 1{ }^{\circ} \mathrm{C}\right)$. The potentiodynamic diagrams were measured from -50 to $50 \mathrm{~V}$ at a rate scan $1 \mathrm{mV} \mathrm{S}^{-1}$ after the steady state is approached $(30 \mathrm{~min})$ and the open potential circuit was observed after putted the electrode for $15 \mathrm{~min}$ in the solution test. The $(\theta)$ and \% IE were measured from Eq. (1):

$\%$ IE $=\theta \times 100=100 \times\left[1-\left(i^{\circ}{ }_{\text {corr }} / i_{\text {corr }}\right)\right]$ $\mathrm{i}_{\text {corr }}^{0}$ and $\mathrm{i}_{\text {corr }}$ are the current corrosion densities lack and attendance of solution inhibitor, consecutively.

(EFM) and (EIS) tests were obtain by utilized the same methods as before with a Gamry framework system depend on ESA400. EchemAnalyst 5.5 Software was utilized for drawing, graphing and fitting data. EIS tests were done in a range of frequency of $100 \mathrm{kHz}$ to $10 \mathrm{mHz}$ with amplitude of $5 \mathrm{mV}$ peak-to-peak ac signals utilized at respective for potential corrosion. EFM had done utilized 2 frequencies 2 and $5 \mathrm{~Hz}$. The frequency base was $1 \mathrm{~Hz}$. In this research, we utilized a signal perturbation with amplitude of $10 \mathrm{mV}$ for both frequencies perturbation of 2 and $5 \mathrm{~Hz}$. 


\section{SEM-EDX Tests:-}

The surface of C38 steel was obtain by keeping the coins for 3 days putted in 1 M hydrochloric acid with and lack of perfect dose of prop-2-en-1-one derivatives, after abraded mechanically utilized unlike papers emery up to grit size 1200. Then, after this time immersion, the samples were lotion gently with distilled water, carefully dried and mounted into the spectrometer attendance of further treatment. The surface of alloy was tested utilized an X-ray diffractometer Philips (pw-1390) with Cu-tube $\left(\mathrm{CuK}_{\alpha}, 1=1.54051\right.$ Á), (SEM, JOEL, JSM-T20, Japan).

\section{Results and Discussion:-}

\section{PotentiodynamicPolarization Measurements: -}

Polarization tests were done to gain knowledge concerning the kinetics of the cathodic and anodic reactions. Figure 1 shows the polarization behavior of C38 steel electrode in $1 \mathrm{M}$ HClwithout and with unlike dose of inhibitor (1). Figure 1 gives that both the cathodic and anodic reactions are impressive by the putting of investigated prop-2-en-1one derivatives and the protection efficiency improve as the inhibitor dose rise, but the cathodic reaction is more inhibited, i.e the addition of prop-2-en-1-one derivatives lower the anodic liquefaction of alloyand prevent the cathodic reactions. Therefore, prop-2-en-1-one derivatives are play as mixed kind inhibitors.

The data in Table 2 given corrosion current density lower obviously after the appending of inhibitors in 1 molar acid and $\%$ IE rise with higher the dose of inhibitor. The $\mathrm{E}_{\text {corr }}$ with inhibitor was improve with no definite trend, lead to that these inhibitorsplay as mixed-kind inhibitors. \% $\mathrm{IE}_{\mathrm{p}}$ was record by utilized equation:

$$
\left.\% I E_{p}=\left[i_{\text {corr }}-\mathbf{i}_{\text {corr }}\right) / \mathbf{i}_{\text {corr }}{ }^{\mathbf{n}}\right] \mathbf{x 1 0 0}
$$

where $\mathrm{i}_{\text {corr }}$ and $\mathrm{i}^{\mathrm{o}}$ corr are the inhibited and lack inhibited current corrosion densities, respectively.

It is evident from Table 2 that the $\left(\beta_{\mathrm{a}}\right)$ and $\left(\beta_{\mathrm{c}}\right)$ Tafel lines equal upon unchanged appending of organic derivatives, improvement to a nearly parallel set of anodic lines, and almost parallel cathodic curves record too. The inhibitors adsorbed lower the surface area for corrosion without impressive of the mechanism corrosion of alloy in acidic solution ${ }^{[24,25]}$. The orders of \% IE were: $(1)>(2)$. This order may lead to free electron pair in substituent in the molecular structure, $\mathrm{N}_{2}$ atom and $\pi$ electrons on aromatic nuclei of the inhibitor. This method confirmed the rise in ability of (1) to inhibit in acidic corrosion of alloy as analogy to (2).

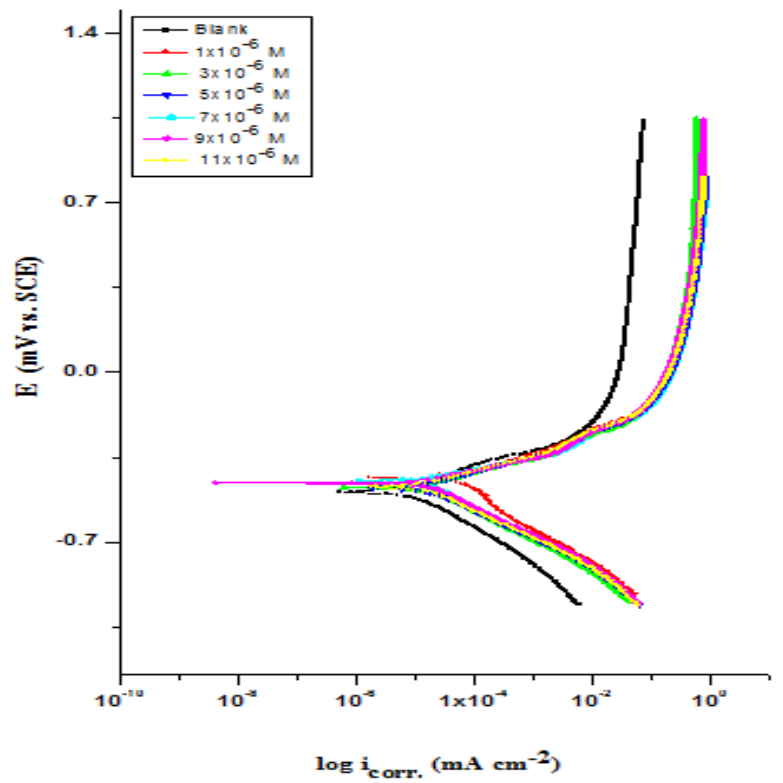

Fig. 1:- Tafel Polarization Diagrams for the Corrosion of C38 Steel in 1 M Hydrochloric Acid Attendance and Lack of Unlike Dose of Inhibitor (1) at $25 \pm 1^{\circ} \mathrm{C}$. 
Table 2:- Concentrations Parameters Effect of Prop-2-en-1-one Derivatives for C38 Steel in 1 Molar Hydrochloric Acid Attendances and Lack of Unlike Dose of Inhibitors at $25 \pm 1^{\circ} \mathrm{C}$.

\begin{tabular}{|c|c|c|c|c|c|c|c|}
\hline Comp. & $\begin{array}{c}\text { Conc., } \\
\text { M. }\end{array}$ & $\begin{array}{c}-\mathbf{E}_{\text {corr }} \\
(\mathbf{m V} \text { vs. SCE) }\end{array}$ & $\begin{array}{l}i_{\text {corr }} \times 10^{-5} \\
\left(\mu \mathrm{A} \mathrm{cm}^{-2}\right)\end{array}$ & $\begin{array}{c}\beta_{\mathrm{a}} \times 10^{-3} \\
\left(\mathbf{m V V} \operatorname{dec}^{-1}\right)\end{array}$ & $\begin{array}{c}\beta_{\mathrm{c}} \times \mathbf{1 0}^{-3} \\
\left(\mathrm{mV} \mathrm{dec} \mathrm{de}^{-1}\right)\end{array}$ & $\boldsymbol{\Theta}$ & $\%$ IE \\
\hline & Blank & 495 & 4.88 & 108 & 144 & ---- & ----- \\
\hline \multirow[t]{6}{*}{ (1) } & $1 \times 10^{-6}$ & 463 & 1.31 & 60 & 132 & 0.7316 & 73.16 \\
\hline & $3 \times 10^{-6}$ & 475 & 1.19 & 90 & 198 & 0.7561 & 75.61 \\
\hline & $5 \times 10^{-6}$ & 497 & 1.17 & 100 & 152 & 0.7602 & 76.02 \\
\hline & $7 \times 10^{-6}$ & 486 & 1.12 & 76 & 122 & 0.7705 & 77.05 \\
\hline & $9 \times 10^{-6}$ & 491 & 1.09 & 80 & 161 & 0.7766 & 77.66 \\
\hline & $11 \times 10^{-6}$ & 446 & 1.04 & 103 & 156 & 0.7869 & 78.69 \\
\hline \multirow[t]{6}{*}{ (2) } & $1 \times 10^{-6}$ & 455 & 1.44 & 33 & 41 & 0.7049 & 70.49 \\
\hline & $3 \times 10^{-6}$ & 491 & 1.40 & 87 & 125 & 0.7131 & 71.31 \\
\hline & $5 \times 10^{-6}$ & 478 & 1.38 & 51 & 134 & 0.7172 & 71.72 \\
\hline & $7 \times 10^{-6}$ & 466 & 1.31 & 82 & 119 & 0.7316 & 73.16 \\
\hline & $9 \times 10^{-6}$ & 487 & 1.26 & 60 & 113 & 0.7418 & 74.18 \\
\hline & $11 \times 10^{-6}$ & 438 & 1.18 & 105 & 156 & 0.7585 & 75.85 \\
\hline
\end{tabular}

\section{(EIS) Tests:-}

EIS is a powerful method in the research of corrosion. Mechanistic information, properties of surface and kinetics of electrode can be given from impedance plots ${ }^{[26-30]}$. Figure 2 given Nyquist (a) and Bode (b) curves given at opencircuit potential both in lack and attendance of rising dose of investigated prop-2-en-1-one derivatives. The improvement in the size of the capacitive loop with the appending of prop-2-en-1-one derivatives gives that a gradually barrier forms on the alloy surface. The rise in the size of capacitive loop Figure 2(a) enhances, at a fixed inhibitor dose, obeyed the order: (1) > (2).

The Nyquist diagrams do not give best semicircles as theory expected of EIS. The change from ideal semicircle due to the dispersion of frequency ${ }^{[31]}$ as well as to the inhomogeneity's of the surface. EIS of the additives organic were calculated utilized the equivalent circuit, Figure 3 , the best fit circuit in our experimental data results ${ }^{[32]}$. The $\mathrm{C}_{\mathrm{dl}}$ (double layer capacitance) is measured from Eq. (3):

$$
C_{\mathrm{dl}}=\mathbf{Y}_{0} \omega^{\mathrm{n}-1} / \sin [\mathrm{n}(\pi / 2)]
$$

where $Y_{\mathrm{o}}=$ CPE magnitude, $\omega=2 \pi \mathrm{f}_{\max }, \mathrm{f}_{\max }=$ the imaginary frequency at which the component of the impedance is maximal.

After test the shape of the Nyquist curves, the corrosion process was controlled mainly charged-transfer ${ }^{[33-36]}$. From the EIS data (Table 3), we noted that the data of $\mathrm{R}_{\mathrm{ct}}$ rise with rising the dose of the inhibitors and this lead to a rise in $\%$ IE, which in obeys with the mass reduction results given. Data of capacitance double layer are also lower to the maximum inhibitor extent. The lower in $\mathrm{CPE} / \mathrm{C}_{\mathrm{dl}}$ data from a lower in local dielectric constant and/or an improve in

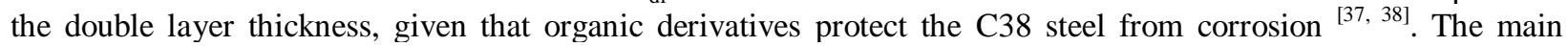
advantages of EIS are to follow the corrosion behavior of the metal with constant time. The inhibition efficiency was calculated from the charge transfer resistance data from equation (4) ${ }^{[39]}$ :

$\% \mathrm{IE}_{\mathrm{EIS}}=\left[1-\left(\mathbf{R}_{\mathrm{ct}}^{\circ} / \mathbf{R}_{\mathrm{ct}}\right)\right] \times 100$

where $\mathrm{R}_{\mathrm{ct}}^{\circ}$ and $\mathrm{R}_{\mathrm{ct}}$ are the charge-transfer resistance values without and with inhibitor, consecutively. 

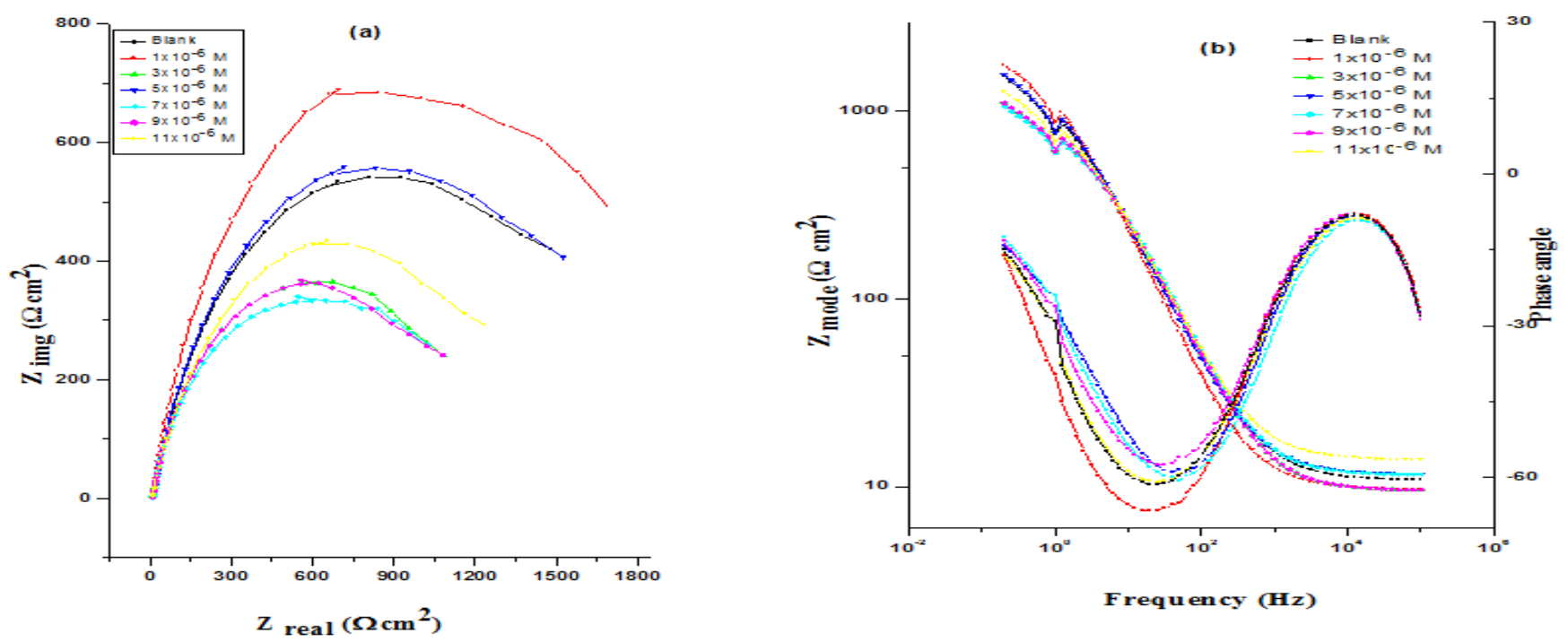

Fig. 2:- EIS Nyquist (a) and Bode Diagrams (b) for the Corrosion of C38 Steel in 1 M Hydrochloric Acid Attendance and Lack of Unlike Dose of Inhibitor (1) at $25 \pm 1^{\circ} \mathrm{C}$.

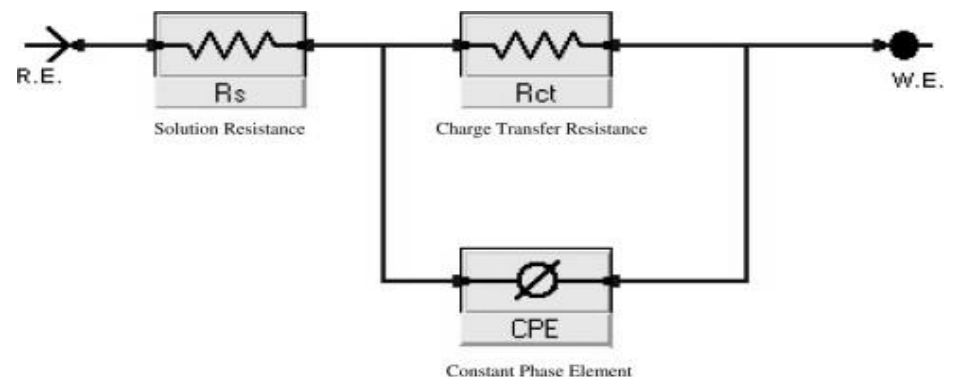

Fig. 3:- Circuit Equivalent Utilized to Fit EIS Data.

Table 3:- Kinetic Parameters Given by EIS Test for C38 Steel in 1 M Hydrochloric Acid Attendance and Lack of Unlike Dose of Prop-2-en-1-one Derivatives at $25 \pm 1{ }^{\circ} \mathrm{C}$.

\begin{tabular}{|c|c|c|c|c|c|c|c|c|}
\hline Comp. & Conc., M. & $\begin{array}{c}R_{S} \times 10^{-3} \\
\left(\Omega \mathrm{cm}^{2}\right)\end{array}$ & $Y_{o} \times 10^{-6}$ & $n \times 10^{-3}$ & $\begin{array}{c}R_{\mathrm{ct}} \times \mathbf{1 0}^{-3} \\
\left(\Omega \mathrm{cm}^{2}\right)\end{array}$ & $\begin{array}{l}C_{d l} \times 10^{-5} \\
\left(\mu \mathrm{Fcm}^{-2}\right)\end{array}$ & $\boldsymbol{\Theta}$ & IE \\
\hline & Blank & 11.09 & 18.15 & 1.00 & 36.86 & 8.93 & ----- & ------ \\
\hline \multirow[t]{6}{*}{ (1) } & $1 \times 10^{-6}$ & 9.70 & 12.55 & 1.02 & 178.0 & 1.24 & 0.793 & 79.3 \\
\hline & $3 \times 10^{-6}$ & 9.72 & 12.26 & 1.03 & 178.6 & 1.23 & 0.794 & 79.4 \\
\hline & $5 \times 10^{-6}$ & 10.63 & 12.68 & 1.12 & 194.7 & 1.22 & 0.811 & 81.1 \\
\hline & $7 \times 10^{-6}$ & 10.58 & 16.75 & 1.04 & 220.1 & 1.29 & 0.833 & 83.3 \\
\hline & $9 \times 10^{-6}$ & 9.60 & 16.24 & 1.07 & 361.7 & 1.20 & 0.898 & 89.8 \\
\hline & $11 \times 10^{-6}$ & 9.70 & 12.26 & 1.06 & 428.1 & 1.19 & 0.914 & 91.4 \\
\hline \multirow[t]{6}{*}{ (2) } & $1 \times 10^{-6}$ & 9.47 & 8.93 & 1.04 & 78.61 & 1.67 & 0.531 & 53.1 \\
\hline & $3 \times 10^{-6}$ & 11.32 & 18.30 & 1.03 & 105.3 & 1.31 & 0.659 & 65.0 \\
\hline & $5 \times 10^{-6}$ & 13.82 & 13.00 & 1.05 & 112.3 & 1.30 & 0.672 & 67.2 \\
\hline & $7 \times 10^{-6}$ & 15.86 & 19.80 & 1.12 & 119.5 & 1.29 & 0.692 & 69.2 \\
\hline & $9 \times 10^{-6}$ & 9.71 & 12.55 & 1.04 & 123.2 & 1.26 & 0.701 & 70.1 \\
\hline & $11 \times 10^{-6}$ & 11.07 & 19.02 & 1.06 & 134.2 & 1.25 & 0.725 & 72.5 \\
\hline
\end{tabular}

EFM Method:-

The advantages of EFM test give it an ideal for online monitoring of corrosion ${ }^{[40]}$. The causality factors is higher strength data of the EFM which act as an internal check on verified data and of the EFM test. The CF-2 and CF-3 are record from the frequency spectrum of the responses current. The data of (EFM) in acidic solution with and 
without various doses of prop-2-en-1-one derivatives given in Figure 4. The same plots were obtained for other compound (not shown). The two higher peaks, with amplitude of about $200 \mu \mathrm{A}$, are the given to the 40 and 100 $\mathrm{mHz}(2$ and $5 \mathrm{~Hz}$ ) excitation frequencies. The EFM experimental data were utilized two unlike models: diffusion complete control of the cathodic reaction and the "activation" model ${ }^{[41]}$. The higher peaks were utilized to measure the ( $\left.i_{\text {corr }}\right),\left(C F-2\right.$ and CF-3) and $\left(\beta_{\mathrm{c}}\right.$ and $\left.\beta_{\mathrm{a}}\right)$. The EFM parameters were given in Table 4 show that, the appended of any one of tested compounds at a given dose to the acidic solution lower the current corrosion density, lead to these compounds protect the corrosion of alloy through adsorption. The best data of CF-2 and CF-3 in Table 4 are similar to their theoretical data of 2.0 and 3.0, respectively lead to the calculated value are quality good.

The $\% \mathrm{IE}_{\mathrm{EFM}}$ improves by raising the inhibitor dose and was measured from equation (5):

$\% \mathrm{IE}_{\mathrm{EFM}}=\left[1-\left(\mathbf{i}_{\text {corr }} i^{\mathbf{0}}{ }_{\text {corr }}\right)\right] \mathbf{x} 100$

where $i_{\text {corr }}$ and $i_{\text {corr }}$ are current corrosion densities without and with inhibitor, consecutively.

The order of $\% \mathrm{IE}_{\mathrm{EFM}}:(1)>(2)$.

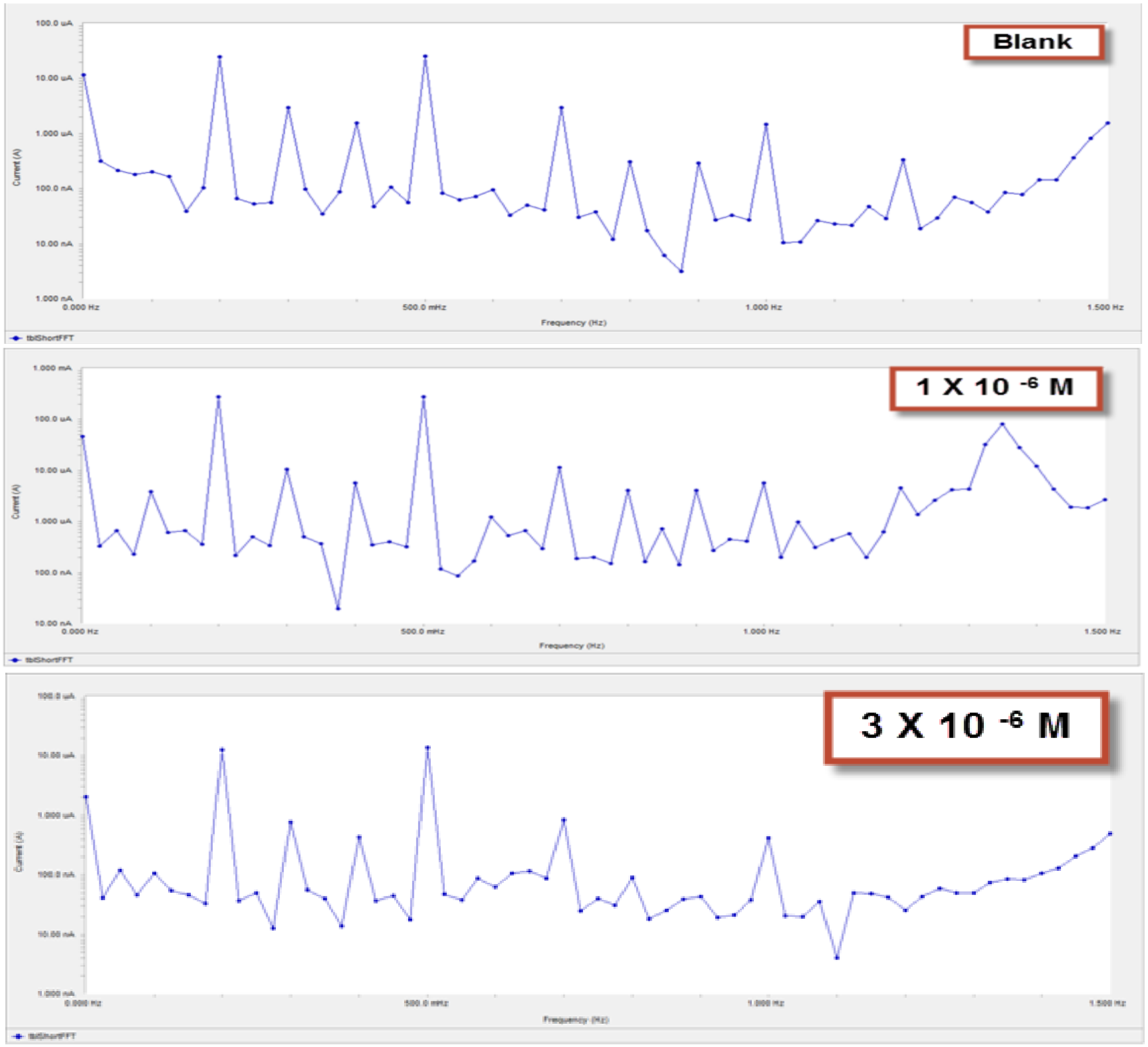




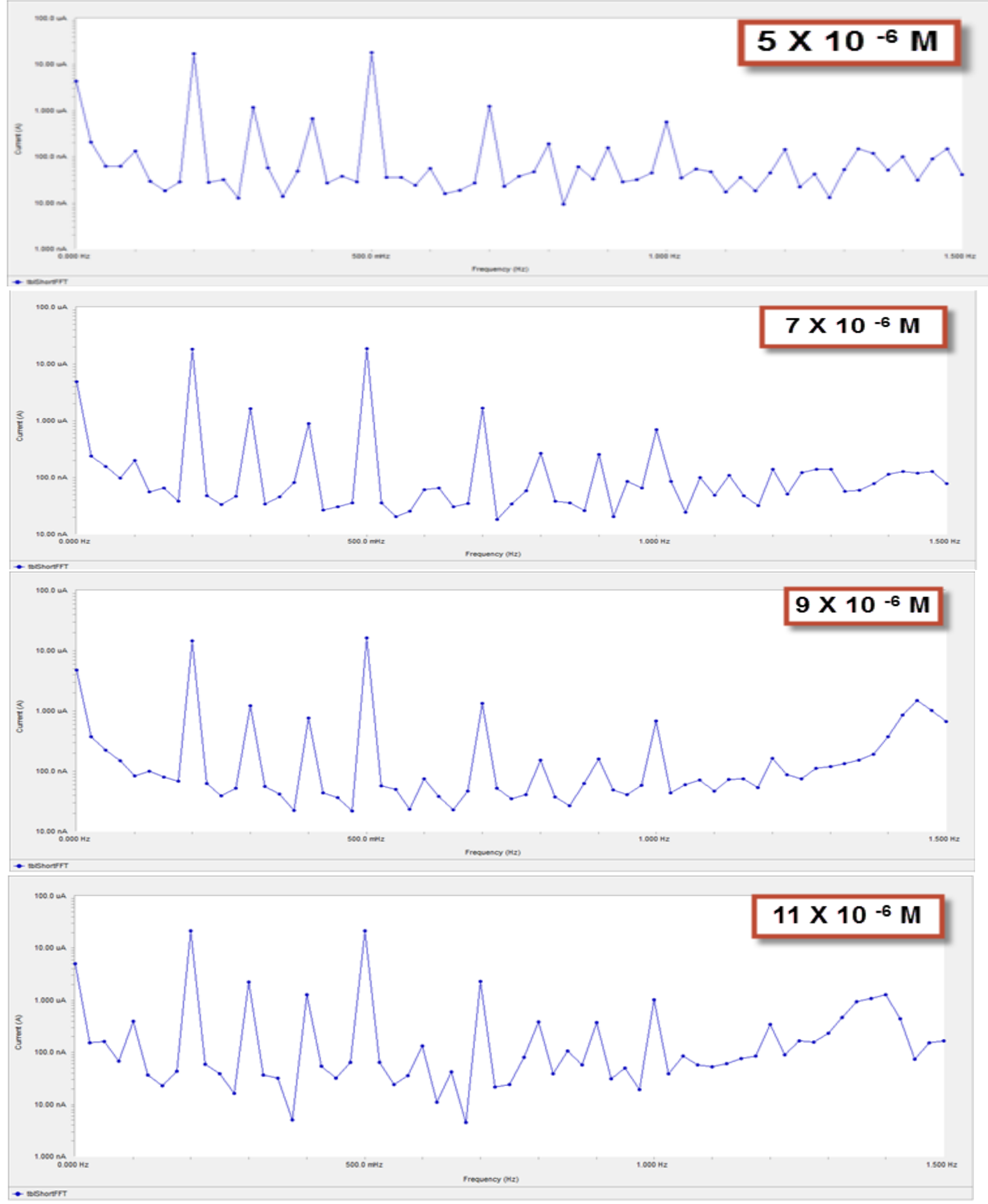

Fig. 4:- EFM Spectra for the Corrosion of C38 Steel in 1 M Hydrochloric Acid Attendance and Lack of Unlike Doseof Inhibitor (1) at $25 \pm 1^{\circ} \mathrm{C}$. 
Table 4:- Electrochemical Kinetic Parameters Obtained by EFM Technique for C38 Steel in $1 \mathrm{M} \mathrm{HCl}$ without and with Various Concentrations of Prop-2-en-1-one Derivatives at $25 \pm 1{ }^{\circ} \mathrm{C}$.

\begin{tabular}{|c|c|c|c|c|c|c|c|c|}
\hline Comp. & $\begin{array}{c}\text { Conc., } \\
\text { M. }\end{array}$ & $\begin{array}{c}\mathbf{i}_{\text {corr }} \\
\left(\mu \mathrm{cm}^{-2}\right)\end{array}$ & $\begin{array}{c}\beta_{\mathrm{a}} \times 10^{-3} \\
\left(\mathrm{mV} \operatorname{dec}^{-1}\right)\end{array}$ & $\begin{array}{c}\beta_{\mathrm{c}} \times 10^{-3} \\
\left(\mathrm{mV} \operatorname{dec}^{-1}\right)\end{array}$ & CF-2 & CF-3 & $\Theta$ & $\%$ IE \\
\hline & Blank & 57.24 & 97 & 328 & 1.99 & 2.79 & ----- & ------ \\
\hline \multirow[t]{6}{*}{ (1) } & $1 \times 10^{-6}$ & 22.00 & 87 & 352 & 1.96 & 2.93 & 0.6157 & 61.57 \\
\hline & $3 \times 10^{-6}$ & 19.22 & 83 & 129 & 1.88 & 2.81 & 0.6642 & 66.42 \\
\hline & $5 \times 10^{-6}$ & 15.23 & 87 & 146 & 1.84 & 2.95 & 0.7339 & 73.39 \\
\hline & $7 \times 10^{-6}$ & 14.89 & 73 & 105 & 1.85 & 3.17 & 0.7399 & 73.99 \\
\hline & $9 \times 10^{-6}$ & 11.52 & 46 & 49 & 1.99 & 3.09 & 0.7987 & 79.87 \\
\hline & $11 \times 10^{-6}$ & 9.53 & 54 & 68 & 2.09 & 2.62 & 0.8335 & 83.35 \\
\hline \multirow[t]{6}{*}{ (2) } & $1 \times 10^{-6}$ & 32.44 & 97 & 191 & 2.02 & 2.95 & 0.4333 & 43.33 \\
\hline & $3 \times 10^{-6}$ & 30.07 & 120 & 225 & 2.11 & 2.80 & 0.4747 & 47.47 \\
\hline & $5 \times 10^{-6}$ & 29.70 & 79 & 90 & 2.01 & 2.89 & 0.4811 & 48.11 \\
\hline & $7 \times 10^{-6}$ & 27.71 & 91 & 195 & 1.93 & 3.01 & 0.5159 & 51.59 \\
\hline & $9 \times 10^{-6}$ & 26.95 & 92 & 165 & 1.92 & 2.76 & 0.5292 & 52.92 \\
\hline & $11 \times 10^{-6}$ & 26.73 & 84 & 160 & 1.82 & 3.04 & 0.5392 & 53.92 \\
\hline
\end{tabular}

(SEM) Tests:-

The micrography given from coins of C38 steel without and with of $11 \times 10^{-6}$ Mprop-2-en-1-one derivatives after putted for 3 days given in Figure 5. The surfaces suffer from severe corrosion attack in the blank sample. Due to the stress out when the compound adding in the solution, the morphology of alloy surfaces is quite unlike from the preceding one, and the tests surfaces were smoother. We observed a film formation which distributed in a random way on the whole alloy surface. This may be interpreted as due to the adsorption of the prop-2-en-1-one derivatives on C38 steel surface merger into the passive film in order to the active site block on alloy. Resulting in a lower in the contact among alloy and the aggressive medium and sequentially obtain best inhibition effect ${ }^{[42,43]}$.

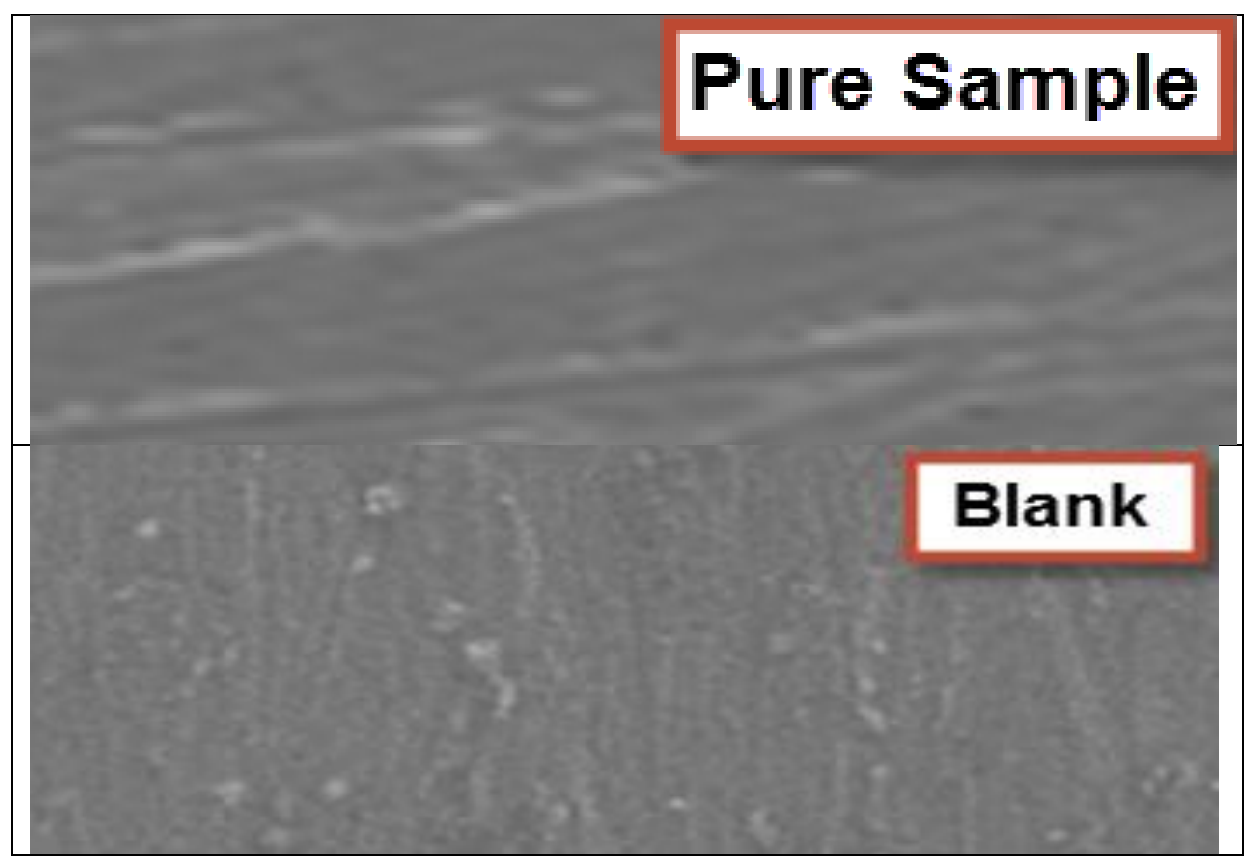




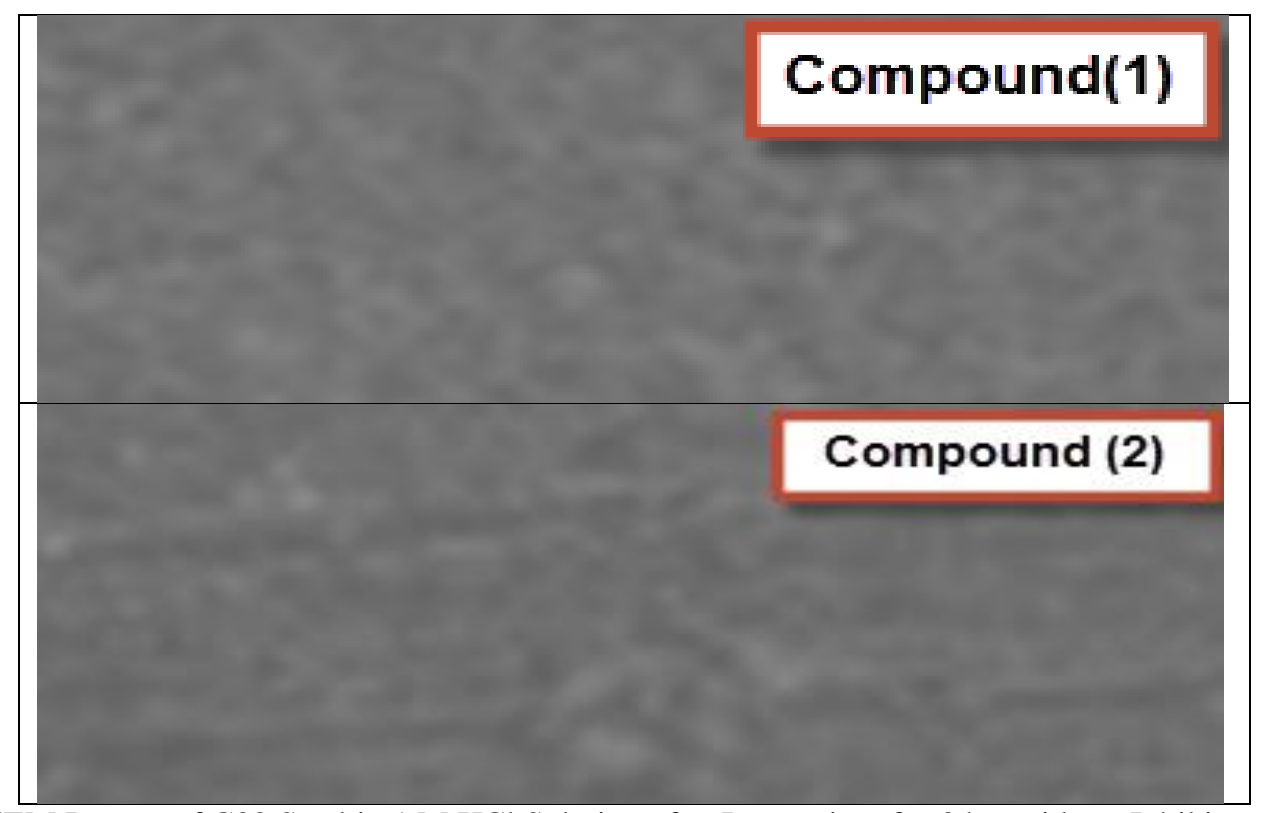

Fig. 5:- SEM Images of $\mathrm{C} 38 \mathrm{Steel}$ in $1 \mathrm{M} \mathrm{HCl}$ Solution after Immersion for $3 \mathrm{hrs}$ without Inhibitor and with of $11 \times 10^{-6} \mathrm{M}$ of Prop-2-en-1-one Derivatives.

(EDS) Test:-

The EDS spectra were utilized to measure the elements found on the surface of C38 steel and after 3 days of covered in the lack and attendance of $1 \mathrm{M} \mathrm{HCl}$. Figure 6 gives the EDS result measured on the composition of $\mathrm{C} 38$ steel only without the acid and inhibitor modified. The EDS record that only oxygen and iron were observed, which given that the passive film found with only $\mathrm{Fe}_{2} \mathrm{O}_{3}$.

The EDS tests of $\mathrm{C} 38$ steel in $1 \mathrm{M} \mathrm{HCl}$ only and with of $11 \times 10^{-6} \mathrm{M}$ of prop-2-en-1-one derivatives portrays in Figure 6. The spectra give additional lines, lead to the presence of $\mathrm{C}$ (the carbon atoms of prop-2-en-1-one derivatives). These values give that the $\mathrm{O}$ and $\mathrm{C}$ atoms covered surface. The elemental observed is record in Table 5.

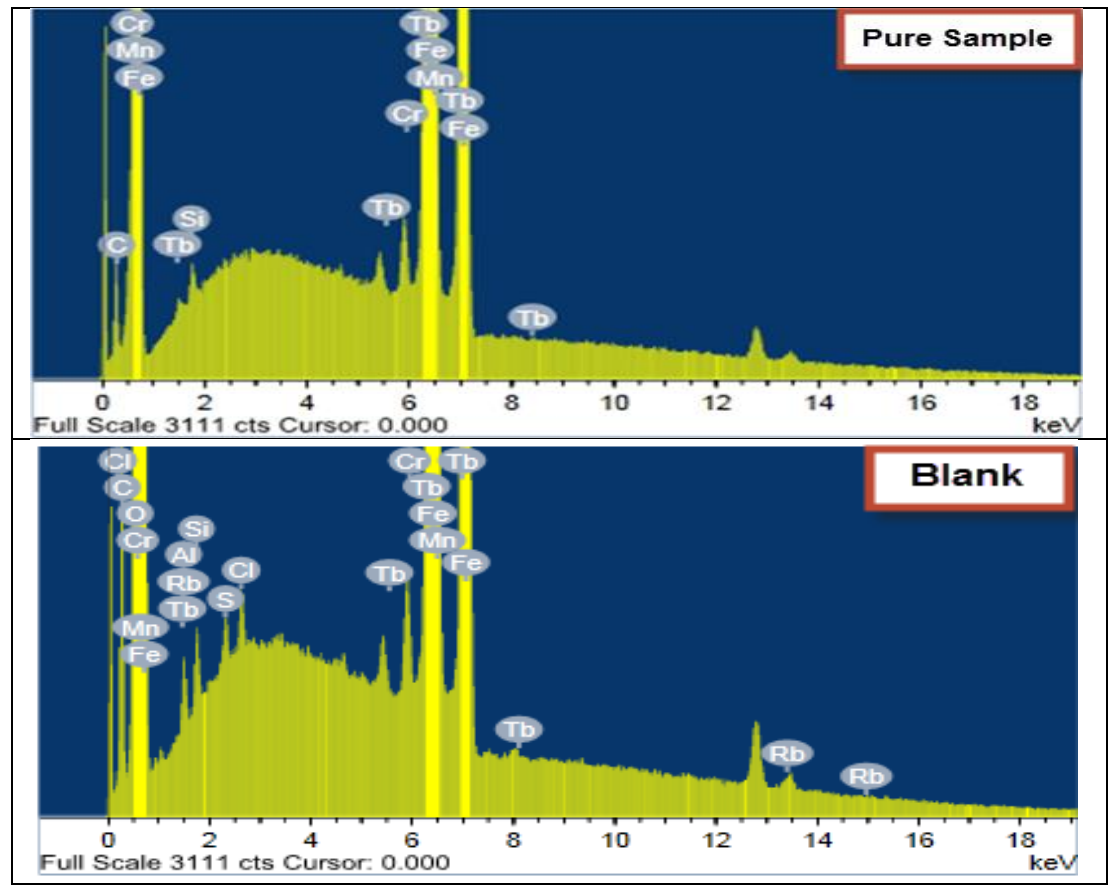




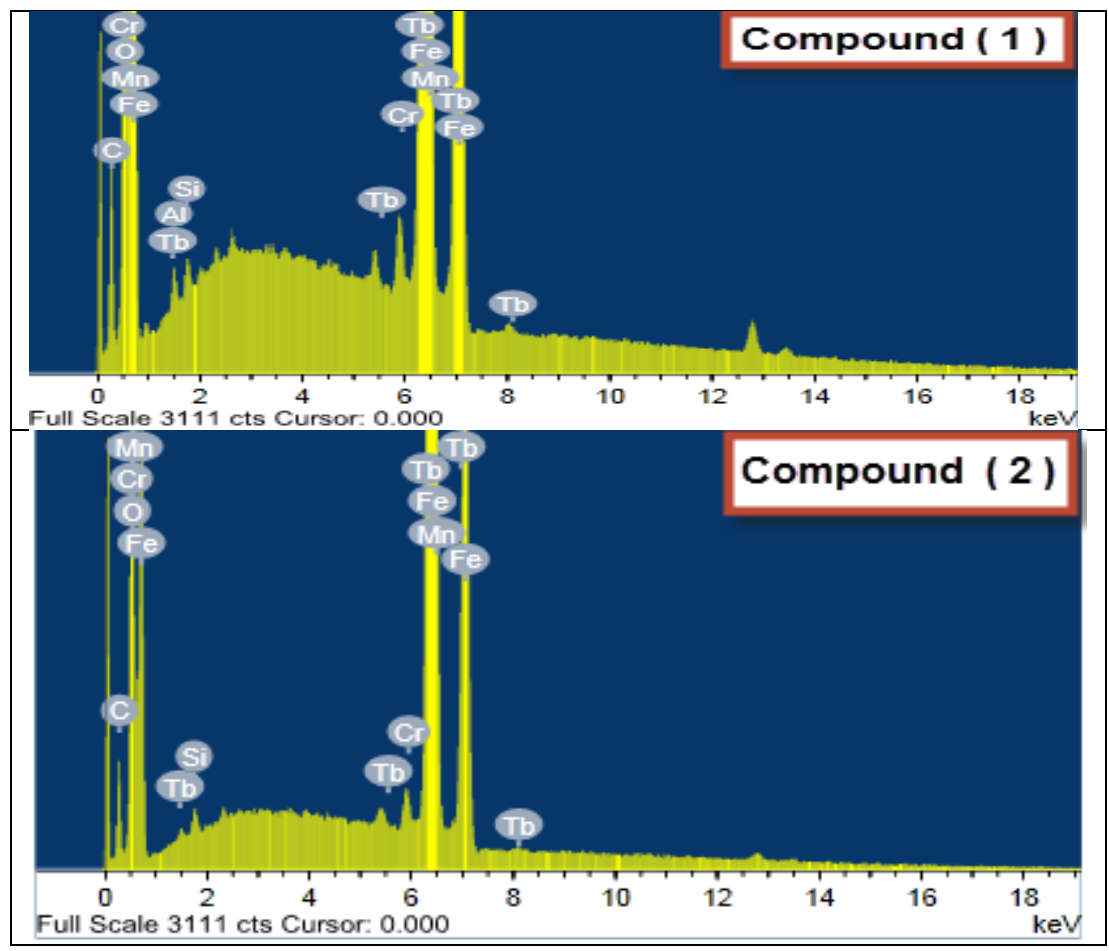

Fig. 6:- EDS Study of C38 Steel in $1 \mathrm{M} \mathrm{HCl}$ Solution after Immersion for 3hrs without Inhibitor and in Presence of $11 \times 10^{-6} \mathrm{M}$ of Prop-2-en-1-one Derivatives.

Table 5:- Wt\% of C38 Steel after 3 Days in HClLack and Attendance of the Optimum Dose of the Studied Prop-2en-1-one Derivatives.

\begin{tabular}{|c|c|c|c|c|c|c|c|c|c|c|c|}
\hline (Mass \%) & C & O & Al & Si & S & Cl & Cr & Mn & Fe & Rb & Tb \\
\hline Pure Sample & 8.91 & ---- & 0.06 & 0.27 & --- & ---- & 0.21 & 0.55 & 86.77 & ---- & 3.23 \\
\hline Blank & 7.89 & 16.54 & 0.34 & 0.29 & 0.13 & 0.16 & 0.18 & 0.41 & 71.26 & 0.44 & 2.36 \\
\hline Compound (1) & 13.48 & 13.40 & 0.30 & 0.22 & --- & --- & 0.18 & 0.41 & 70.90 & ---- & 1.11 \\
\hline Compound (2) & 12.27 & 13.75 & ----- & 0.27 & ----- & ---- & 0.16 & 0.41 & 70.59 & ---- & 2.55 \\
\hline
\end{tabular}

\section{Mechanism of Corrosion Protection;-}

From the electrochemical experiments the \% IE relies on dose, metal nature, surface conditions and the type of inhibitors adsorption on C38 steel.

The results of corrosion value attendance of these inhibitors:

i) The lower of rate and current of corrosion with rise in dose of the inhibitor.

ii) The change in Tafel lines to maximum regions of potential.

iii) The lower in \%IEcorrosion with improve temperature lead to desorption of the adsorbed inhibitor molecules obtain.

iv) The \%IE relies on charge density and their equipment of adsorption centers in the molecule.

It was observed that the type of adsorption relies on the affinity of the C38 steel towards the clouds of $\pi$-electron of the ring. Metals such as iron, which have a higher attract towards aromatic moieties, were obtain to adsorb benzene rings in orientation flat. The order of lowering the \% IE are given: $1>2$.

Compound (1) exhibits excellent inhibition power due to: (i) the presence ofp- $\mathrm{OCH}_{3}$ group which is an electron donating group with negative Hammett constant $(\sigma=-0.27)$, Also this group will increase the electron charge density on the molecule,(ii) its larger molecular size that may facilitate better surface coverage, and (iii) its adsorption through two active centers. Compound (2) has the lowest inhibition efficiency. This is due to presence of $\mathrm{p}-\mathrm{Cl}$ which has positive Hammett constant $(\sigma=+0.23)$, i.e. group which lower the electron density on the molecule and hence, lower inhibition efficiency. 


\section{Conclusion:-}

* All the investigated compounds are good corrosion inhibitors for C38 steel in $1 \mathrm{M} \mathrm{HCl}$ solution. The effectiveness of these inhibitors depends on their structures. The variation in inhibitive efficiency depends on the type and the nature of the substituent present in the inhibitor molecule.

* Double layer capacitances decrease with respect to blank solution when the inhibitor added. This fact may explained by adsorption of the inhibitor molecule on the C38 steel surface.

* EFM can be utilized as a fast and nondestructive tests for calculation of corrosion without prior information of Tafel lines

* The data from electrochemical tests were in best agreement. The \% IE of these compounds investigated is: $1>$ 2.

* The heteroatoms $\mathrm{N}$ and $\mathrm{O}$ are the active sites ofthe prop-2-en-1-one derivatives. It can adsorb on Fe surface firmly by donating electrons to $\mathrm{Fe}$ atoms and accepting electrons from $3 \mathrm{~d}$ orbital of $\mathrm{Fe}$ atoms.

\section{References:-}

1. M.H. Wahdan, A.A. Hermas, M.S. Morad, Mater. Chem. Phys. 76 (2002) 111-118.

2. F. Bentiss, M. Lebrini, H. Vezin, M. Lagrenee, Mater. Chem. Phys. 87 (2004) 18-23.

3. X. Liu, P.C. Okafor, Y.G. Zheng, Corros. Sci. 51 (2009) 744-751.

4. A. Al Maofari, G. Ezznaydy, Y. Idouli, F. Guedira, S. Zaydoun, N. Labjar and S. El Hajjaji, J. Mater. Environ. Sci. 5 (2014) 2081-2085.

5. K. Barouni, A. Kassale, A. Albourine, O. Jbara, B. Hammouti, L. Bazzi, J. Mater. Environ. Sci. 5 (2014) 456463.

6. A.S. Fouda, K. Shalabi, H. Elmogazy, J. Mater. Environ. Sci. 5 (2014) 1691-1702.

7. A. Ostovari, S.M. Hoseinieh, M. Peikari, S.R. Shadizadeh, S.J. Hashemi, Corros. Sci. 51 (2009) 1935-1949.

8. M.J. Bahrami, S.M.A. Hosseinia, P. Pilvar, Corros. Sci. 52 (2010) 2793-2803.

9. M.M. Solomon, S.A. Umoren, I.I. Udosoro, A.P. Udoh, Corros. Sci. 52 (2010) 1317-1325.

10. H.L. Wang, R.B. Liu, J. Xin, Corros. Sci. 46 (2004) 2455-2466.

11. R. Solmaz, G. Kardas, B. Yazici, M. Erbil, Prot. Met. 41 (2005) 581-585.

12. K.C. Emregul, R. Kurtaran, O. Atakol, Corros. Sci. 45 (2003) 2803-2817.

13. D. Chebabe, Z.A. Chikh, N. Hajjaji, A. Srhiri, F. Zucchi, Corros. Sci. 45 (2003) 309-320.

14. F.G. Liu, M. Du, J. Zhang, M. Qiu, Corros. Sci. 51 (2009) 102-109.

15. A.Y. Musa, A.A.H. Kadhum, A.B. Mohamad, M.S. Takriff, Corros. Sci. 52 (2010) 3331-3340.

16. K.F. Khaled, M.A. Amin, Corros. Sci. 51 (2009) 1964-1975.

17. M.A. Quraishi, M.Z.A. Rafiquee, S. Khan, N. Saxena, J. Appl. Electrochem. 37 (2007) 1153-1162.

18. X.Y. Zhang, F.P. Wang, Y.F. He, Y. Du, Corros. Sci. 43 (2001)1417-1431.

19. M. Knag, K. Bilkova, E. Gulbrandsen, P. Carlsen, J. Sjoblöm, Corros. Sci. 48 (2006) 2592-2613.

20. L. Wang, G.J. Yin, J.G. Yin, Corros. Sci. 43 (2001) 1197-1202.

21. P.C. Okafor, X. Liu, Y.G. Zheng, Corros. Sci. 51 (2009) 761-768.

22. J. Zhang, J.X. Liu, W.Z. Yu, Y.G. Yan, L. You, L.F. Liu, Corros. Sci. 52 (2010) 2059-2065.

23. R.F.Anderson, S. S. Shinde, A.Maroz.Org. Biomol. Chem. 6(2008) 1973.

24. S. Martinez, I. Stern, Appl.Surf.Sci. 199 (2002) 83-89.

25. M.A. Al-Khaldi, K.Y. Al-qahtani, J. Mater. Environ. Sci. 4 (5) (2013) 593-600.

26. J.W. Schltze, K. Wippermann, Electrochim. Acta 32 (1987) 823-831.

27. D.C. Silverman, J.E. Carrico, Corrosion 44 (1988) 280- 287.

28. D.D. Macdonald, M.C.H. Mckubre, "Impedance measurements in electrochemical systems" Modern Aspects of Electrochemistry, J. O’M. Bockris, B.E. Conway, R.E. White, Eds., Plenum Press, New York 141982 pp. 61150.

29. F. Mansfeld, Corrosion 36 (1981) 301-307.

30. C. Gabrielli, "Identification of Electrochemical processes by Frequency Response Analysis" Solarton Instrumentation Group, 1980.

31. M. El Achouri, S. Kertit, H.M. Gouttaya, B. Nciri, Y. Bensouda, L. Perez, M.R. Infante, K. Elkacemi, Prog. Org. Coat. 43 (2001) 267-273.

32. A. Anejjar, A. Zarrouk, R. Salghi, H. Zarrok, D. Ben Hmamou, B. Hammouti, B. Elmahi, S.S. Al-Deyab, J. Mater. Environ. Sci. 4 (2013) 583-592.

33. S.F. Mertens, C. Xhoffer, B.C. Decooman, E. Temmerman, Corrosion 53 (1997) 381-388.

34. G. Trabanelli, C. Montecelli, V. Grassi, A. Frignani, J. Cem. Concr. Res. 35 (2005) 1804-1813. 
35. A.J. Trowsdate, B. Noble, S.J. Haris, I.S.R. Gibbins, G.E. Thomson, G.C. Wood, Corros. Sci. 38 (1996) 177191.

36. F.m. Reis, H.G. de Melo, I. Costa, J. Electrochem. Acta 51 (2006) 1780-1788.

37. M. Lagrenée, B. Mernari, M. Bouanis, M. Traisnel, F. Bentiss, Corros. Sci. 44 (2002) 573-588.

38. E. McCafferty, N. Hackerman, J. Electrochem. Soc.119 (1972) 999-1009.

39. H. Ma, S. Chen, L. Niu, S. Zhao, S. Li, D. Li, J. Appl. Electrochem. 32 (2002) 65-72.

40. E. Kuş, F. Mansfeld, Corros. Sci. 48 (2006) 965-979.

41. G.A. Caigman, S.K. Metcalf, E.M. Holt, J. Chem. Cryst. 30 (2000) 415-422.

42. F. Samie, J. Tidblad, V. Kucera, C. Leygraf, Atmospheric Environ. 39 (2005) 7362-7373.

43. R.A. Prabhu, T.V. Venkatesha, A.V. Shanbhag, G.M. Kulkarni, R.G. Kalkhambkar, Corros. Sci. 50 (2008) 3356. 